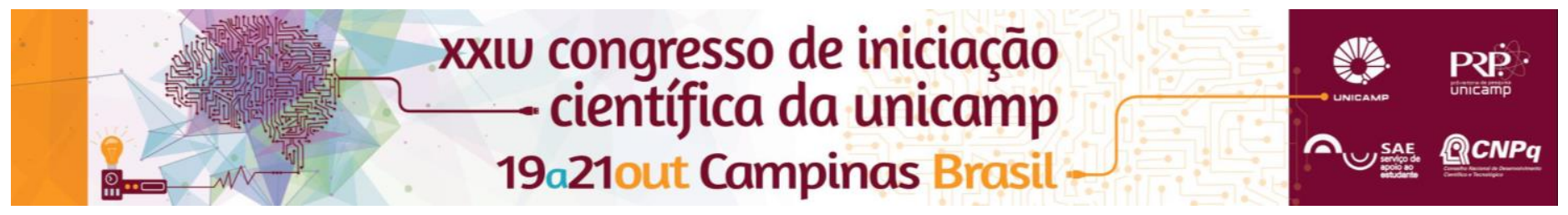

\title{
Nanoestruturas poliméricas para veiculação de peptídeos antimicrobianos com potencial leishmanicida
}

\author{
Marília Medeiros*, Juliana S. R. Costa, Laura de O. Nascimento.
}

\begin{abstract}
Resumo
A leishmaniose cutânea é uma doença causada por protozoários do gênero Leishmania, principalmente a L. amazonensis e brasiliensis em nosso país. É considerada doença negligenciada pela OMS, sendo que no Brasil ocorre predominantemente nas regiões Norte e Nordeste. Os tratamentos disponíveis atualmente para a leishmaniose cutânea apresentam alta toxicidade e requerem hospitalização do paciente. Este trabalho propõe o desenvolvimento e avaliação físico-química de nanopartículas polímericas capazes de carrear polimixina B, um peptídio antimicrobiano com ação leishmanicida, como alternativa no tratamento da leishmaniose cutânea.
\end{abstract}

\section{Palavras-chave:}

Leishmaniose cutânea, nanopartículas, polimixina B.

\section{Introdução}

A leishmaniose é uma doença causada por um protozoário parasita intracelular. Esta doença pode se manifestar nas formas visceral e tegumentar americana (LTA), que pode acometer mucosas ou a pele. No Brasil em 2013 foram notificados 18.226 casos de LTA, sendo que a maior parte desses pertenciam a manifestação cutânea1. A leishmaniose cutânea causa uma resposta inflamatória na derme capaz de levar a formação de ulcerações. Os tratamentos disponíveis atualmente para a doença devem ser administrados por via endovenosa em hospitais por um período de 10 a 40 dias. Essa aplicação torna-se um incômodo ao paciente diminuindo a adesão ao tratamento, além de poder apresentar efeitos adversos devido à toxicidade dos medicamentos².

A polimixina B é um peptídeo antimicrobiano, que foi identificado como potencial inibidor do crescimento de Leishmania ${ }^{3}$. No entanto, é rapidamente hidrolisado por peptidases. Para proteger o fármaco e prolongar seu tempo de ação, este pode ser encapsulado em nanopartículas. Essas estruturas podem ser produzidas a partir de monômeros de polímeros, por exemplo, os quais podem carrear e prolongar a liberação de fármacos no organismo, além de ter potencial redução da toxicidade.

Esse trabalho visa desenvolver e avaliar as características físico-químicas de nanopartículas produzidas a partir do polímero sintético biodegradável n-polibutil-cianoacrilato (PBCA) para veiculação do peptídeo antimicrobiano de escolha, polimixina $B$.

\section{Resultados e Discussão}

Através da metodologia de polimerização em emulsão ${ }^{4}$ proposta para produção de nanopartículas de PBCA (PBCAnp) foi possível obter nanopartículas vazias (PBCAnp-b), assim como PBCAnp-p1, com $1 \mathrm{mg} / \mathrm{mL}$ de polimixina B, PBCAnp-p5 (5 mg/mL) e PBCAnp-p10 (10 $\mathrm{mg} / \mathrm{mL})$.

A análise de tamanho médio de partícula e potencial zeta $(\zeta)$ das nanopartículas produzidas foi feita utilizando as técnicas de Dynamic Light Scattering (DLS) e Nanoparticule Tracking Analysis (NTA). O tamanho médio medido por DLS foi em torno de $200 \mathrm{~nm}$ para as todas as PBCAnp analisadas, enquanto na medição por
NTA foi em torno de $170 \mathrm{~nm}$. As diferenças observadas se devem às técnicas utilizadas.

A eficiência de encapsulação (EE) da polimixina $B$ nas PBCAnp foi calculada através de método indireto, quantificando a concentração do fármaco no sobrenadante. Para tal, foi utilizado o reagente de BCA (ácido bicinconínico) capaz de quantificar proteínas.

$E E \%=\left(\frac{\text { concentração de fármaco no sobrenadante }}{\text { concentração de fármaco adicionado }}\right) * 100$

O perfil de liberação do da polimixina $B$ nas PBCAnp foi determinado em sistema de célula de difusão de Franz, comparativamente com liberação do fármaco livre. As PBCAnp-p5 apresentaram liberação de $50 \%$ fármaco após 6-7 horas, enquanto o fármaco livre leva 1 hora para atingir a mesma liberação.

Uma análise por microscopia eletrônica de varredura (MEV) foi realizada com PBCAnp-b secas a temperatura ambiente e demonstrou que houve diminuição do tamanho das partículas. Esse fato pode ser atribuído a retirada de água da amostra.

\section{Conclusões}

Nanopartículas de PBCA (PBCAnp) apresentaram tamanho médio variando de 203,7 a 216,9 $\mathrm{nm}$, sendo que as PBCAnp com polimixina B não apresentaram alteração significativa de tamanho. O potencial $\zeta$ muda de um valor negativo nas PBCAnp-b, para positivo nas PBCAnp com polimixina, demonstrando que houve adsorção do fármaco nas nanopartículas. A eficiência de encapsulação mostrou-se inversamente proporcional à quantidade de polimixina $B$ adicionada, sendo $21,6 \%$ a maior eficiência de encapsulação medida, que corresponde à PBCAnp-p1. O perfil de liberação medido demonstrou a liberação sustentada de polimixina $B$ promovida pelas nanopartículas poliméricas.

Faepex, CNPq e Fapesp.

\section{Agradecimentos}

1http://www.paho.org/hq/index.php?option=com_topics\&view=article\&id=29\&It emid=40754, acesso em junho 2016 .

${ }^{2}$ Brajburg, J et Al. Antimicrob Agents Chemother, 1990, 34, 183.

${ }^{3}$ Bektran, S., Duque. Biomédica (Bogotá), 1992, 12, 68.

${ }^{4}$ Couvreur, P.; Vauthier, C. Journal of Controlled Release, 1991, 17, 187. 